\title{
Quando Felipe Neto me ajudou a dar aula: relato de experiência de uma professora de jornalismo diante da hipertransversalidade em tempos de pandemia
}

Carolina Falcão

Pesquisadora de Pós-Doutorado no Programa de Pós-Graduação em Direitos Humanos (PPGDH) da Universidade Federal de Pernambuco (UFPE). Doutora em Comunicação pelo Programa de Pós-Graduação em Comunicação da mesma instituição.

E-mail: carolinacfalcao@gmail.com

Resumo: Neste relato, compartilho minha experiência docente na disciplina de "Teorias do Jornalismo" ao longo do primeiro semestre de 2020, marcada pela adoção compulsória do ensino remoto devido à pandemia da Covid-19. A condução da disciplina, que integra o currículo obrigatório de formação em jornalismo, mostrou como a Covid-19 se tornou uma questão onipresente em todo o semestre, fosse em aspectos burocráticos ou pedagógicos, ao assumir um caráter de hipertransversalidade. O relato mostra, no entanto, como uma pauta "furou" esse agendamento quando os próprios estudantes da disciplina trouxeram para o debate em aula a entrevista concedida pelo youtuber Felipe Neto ao programa Roda Viva, da TV Cultura; a partir dela, foi possível construir toda uma estratégia para tratar de temas como fake news, desinformação e atuais modelos de negócio no jornalismo.

Palavras-chave: ensino remoto emergencial; Covid-19; ensino de jornalismo; hipertransversalidade; cibercultura.
Abstract: In this report, I share my teaching experience with the course Theories of Journalism during the semester of 2020.1, when remote education was compulsorily adopted due to the Covid-19 pandemic. Working on this course, which is part of the mandatory journalism training curriculum, showed me how Covid-19 became a hypertransversal topic throughout the semester, that embraced not only bureaucratic (formulations on the didactic contract) aspects, but also pedagogical questions. The report also shows that the coronavirus agenda was challenged when the students brought to debate an interview given by the Brazilian YouTuber Felipe Neto to the "Roda Viva" TV Show. This interview helped to redefine a strategy to work on topics such as Fake News, misinformation, and current business models in journalism.

Keywords: emergency remote education; Covid-19; journalism teaching; hypertransversality; cyberculture.
Recebido: 16/07/2020

Aprovado: 03/11/2020 


\section{INTRODUÇÃO}

Era uma sexta-feira, 13 de março, quando encerrei, sem saber, minha última aula presencial no centro universitário onde trabalhava, localizado na região metropolitana do Recife (PE), ainda no primeiro semestre de 2020. Discutia, em sala, com uma animada turma de terceiro período do curso de jornalismo, como a premissa das teorias construtivistas influenciam noções de realidade ou de verdade - conceitos importantes para o jornalismo enquanto prática e discurso. Muito embora já houvesse no mundo "lá fora" uma pandemia em andamento", o tema "coronavírus" se deu como uma digressão pontual no decorrer da aula. Havia casos registrados no Brasil e no estado e os números na Itália e Espanha já eram conhecidos, mas de forma alguma supúnhamos, naquela que seria nossa última aula presencial, que não teríamos um próximo encontro para debater as teorias do jornalismo, título da disciplina ministrada.

Levando em conta a distância entre aquela longínqua sexta-feira 13 e o atual momento - pouco menos de quatro meses que, contados pela experiência da quarentena e do isolamento social, parecem mais que dobrar seus quase 120 dias -, é possível dizer que as coisas aconteceram rápido demais. No domingo, 15 de março, o consórcio de universidades e institutos federais do estado informou a suspensão das atividades acadêmicas e administrativas. $\mathrm{Na}$ quarta-feira,18, prefeituras da região metropolitana anunciavam a suspensão das aulas em todos os segmentos (da educação básica à superior, em escolas públicas e privadas), determinação acompanhada também pelo governo do estado. Se na sexta-feira era improvável pensar que não haveria mais um novo encontro presencial com minha turma de terceiro período, na quarta seguinte professoras e professores das redes privadas de ensino já estavam lidando com uma questão urgente: como continuar o semestre acadêmico mesmo com as medidas de isolamento social?

A adoção de plataformas de educação centradas em ferramentas de videoconferência foi a solução encontrada não só por instituições acadêmicas como por organizações de perfis diversos, que também optaram pelo trabalho remoto. No caso apresentado neste trabalho, a plataforma Google Classroom já era de conhecimento da equipe docente da instituição, uma vez que algumas funcionalidades já eram utilizadas com o objetivo de complementação parcial da carga horária das disciplinas. A novidade propriamente dita se deu com a adoção do aplicativo Google Meet, que permitiu a realização de atividades síncronas com as turmas. Dessa forma, o horário de aulas semanais foi mantido devido à utilização das videoconferências; assim, na sexta seguinte, dia 20 de março, eu já poderia me "encontrar" com a turma para darmos prosseguimento ao planejamento acadêmico do primeiro semestre. Em sete dias, uma disciplina de $40 \mathrm{~h}$ pensada para ser ministrada presencialmente e com apenas alguns componentes complementares virtuais (atividades assíncronas), precisou ser reformulada (e executada) a partir de uma plataforma virtual de ensino.

1.OMS DECRETA pandemia mundial por novo coronavírus. O Globo, São Paulo, 11 mar. 2020. Disponível em: https://oglobo.globo. com/sociedade/coronavirus/oms-decreta-pandemia-mundial-por-novo-coronavirus-24298652. Acesso em: 14 jan. 2021. 


\section{comunicação \& educação • Ano XXV • número 2 • jul/dez 2020}

2.Meu argumento baseia-se num editorial publicado pela Associação $\mathrm{Ca}$ nadense de Professores Universitários (CAUT, sigla em inglês): GOING online without any proper help. Canadian Association of University Teachers Ottawa, 1 maio 2020. Disponível em: https://www. caut.ca/bulletin/2020/05/ news-going-online-without-any-proper-help. Acesso em: 14 jan. 2021.

3. MENEZES, Anna Paula de Avelar Brito. Contrato didático e transposição didática: inter-relações entre fenômenos didáticos na iniciação à álgebra na $6^{\mathrm{a} a}$ série do ensino fundamental. 2006. 259 f. Dissertação (Mestrado em Educação) Pós-Graduação em Centro de Educação, Universidade Federal de Pernambuco, Recife, 2006.
Acredito que essa breve retomada do desenvolvimento da pandemia é fundamental para entender como se dão as nuances da prática docente, agora marcada por essa contingência tão específica, inédita e inesperada. Entendo que não se pode pensar essa nova vivência sem o sentido de urgência que a situação instaurou e, também, sem levar em consideração as soluções rápidas que foram estabelecidas pela direção da instituição de ensino e repassadas para o corpo docente. Meu relato começa, portanto, defendendo que a experiência em questão deve ser nomeada, e, consequentemente, problematizada como Ensino Remoto Emergencial ${ }^{2}$ (ou ERE). Assim, argumento que, muito embora o repertório metodológico utilizado ao longo do semestre esteja claramente vinculado às práticas da educação on-line, da educação a distância e do ensino virtual, não são essas as expressões apropriadas para navegar pela experiência docente durante a pandemia da Covid-19.

\section{ENSINO REMOTO EMERGENCIAL, UM INÍCIO}

Três pontos merecem destaque na experiência relatada, principalmente no que se refere ao impacto no desenvolvimento e na execução do planejamento da disciplina ministrada: (1) a configuração de um novo contrato didático; (2) a hipertransversalidade da pandemia; (3) as discussões com os estudantes sobre a entrevista do youtuber brasileiro Felipe Neto ao programa Roda Viva e o impacto dessa interlocução na disciplina. O primeiro ponto informa as negociações da experiência do ERE, o segundo contextualiza essa vivência em sua contingência na pandemia e seu duplo sentido (curricular e burocrático) e o terceiro mostra como a prática docente pode ser pautada mesmo num contexto de excepcional tematização.

Para melhor compreender o momento de ajustes e negociações, quero usar a expressão "contrato didático" com cuidado e de maneira muito específica isso porque o termo pode sugerir uma ideia pragmática de negociação, inclusive num sentido funcionalista-bancário, que não faz parte de minha ética docente. Postulo, a partir de Menezes ${ }^{3}$, que, no entanto, é possível compreender o contrato didático como uma relação de obrigações recíprocas e que determinam (ora explícita, ora implicitamente) as atribuições e responsabilidades de cada parceiro - professores e alunos - num dado contexto.

As primeiras aulas remotas mostraram como esse contrato, muitas vezes implicitamente acordado, precisou ser transformado (e sobretudo negociado) entre professora e turma. O exemplo mais emblemático dessa mudança está no manuseio dos dispositivos de som e áudio. A necessidade de "fechar" o microfone e a câmera de todos os estudantes da turma para melhorar a qualidade de transmissão, diminuindo as interferências naturais do contexto doméstico - dado que a grande maioria dos envolvidos estavam em suas casas no momento das aulas -, também implicava num grande desafio sobre a percepção e o registro formal (na chamada, no acompanhamento processual do 
desempenho) do que seriam "presença" e "participação" dos estudantes por parte da impressão do docente.

Nessa perspectiva, algumas questões práticas foram discutidas no contexto do Ensino Remoto Emergencial: deveria haver uma chamada na metade da aula para ter certeza de que os estudantes conectados estavam de fato presentes e atentos, ou a professora deveria assumir a presença daqueles cujo avatar estivesse sinalizado como on-line? O que fazer com os estudantes que alegam não conseguirem assistir as aulas até o fim devido a limitações técnicas de conexão? Minha experiência na condução dessas negociações mostrou que não há uma reposta certa para essas e outras perguntas que emergiram ao longo do novo semestre; mesmo decisões bem-sucedidas, tomadas numa determinada aula, poderiam não repetir o efeito positivo na mesma turma, mas num encontro seguinte.

Refletindo sobre a natureza do contrato didático, Menezes ${ }^{4}$ explica que, embora importante na formulação de acordos, expectativas, obrigações recíprocas e objetivos, ele não é capaz de traduzir ou mesmo de determinar completamente a relação que se estabelece na sala de aula. No Ensino Remoto Emergencial experimentado nesse primeiro semestre de 2020, os contornos do contrato didático motivaram diversos momentos de interação entre professora e turma, sendo necessárias muitas vezes a revisão de acordos e a discussão sobre práticas que já estavam, de certa forma, pacificadas no ambiente off-line das aulas presenciais.

Refiro-me especificamente às questões de avaliação e prova. Por se tratar de uma turma veterana, os estudantes já conheciam a normativa sobre os processos avaliadores. Nos recorrentes debates sobre o contrato didático, percebi uma turma muito interessada em discutir a competência do processo avaliador como um todo. Entendo e reconheço que esse tipo de demanda (debater/questionar as provas e os trabalhos) é algo que se observa também em encontros off-line, sobretudo quando se trata de disciplinas majoritariamente teóricas; mas não deixou de me surpreender como, em alguns momentos, estávamos debatendo a genealogia de significantes como "prova", "trabalho" e "recuperação". Também entraram em cena questões sobre a própria formação do jornalista e como acontece a construção do currículo do curso. Não me lembro de outro momento, em contexto de aula presencial, em que a temática da formação jornalística tenha entrado de maneira não-planejada na ordem das interações com estudantes. Nesse sentido, foi particularmente gratificante ver como alguns deles, quando provocados, foram capazes de traçar paralelos entre as premissas do Newsmaking ${ }^{5}$ e da educação formal na área, ainda fortemente ligada ao desenvolvimento de aptidões voltadas para as rotinas produtivas majoritariamente industriais do jornalismo.

\section{A QUESTÃO DA HIPERTRANSVERSALIDADE}

À medida que avançávamos no semestre, as discussões sobre o contrato didático foram se tornando cada vez menos necessárias para a realização das aulas. Não quero, com isso, afirmar que houve uma solução definitiva sobre como modalizar a presença/ausência/participação dos estudantes nos encontros.

4. Idem.

5. Teoria construtivista, 0 Newsmaking entende que a notícia não espelha a realidade, mas, sim, atua no processo de construção desta - daí seu interesse pela produção noticiosa como um processo pautado por uma racionalidade industrial. 
6. FREIRE, Paulo. A importância do ato de ler: em três textos que se completam. 3. ed. São Paulo: Autores Associados: Cortez, 1986

7. BRASIL, Ministério da Educação. Instituto Nacional de Estudos e Pesquisas Educacionais Anísio Teixeira. Diretoria de Avaliação da Educação Superior. Sistema Nacional de Avaliação da Educação Superior. Instrumento de avaliação de cursos de graduação: presencial e a distância. Brasília, 20 mar. 2015. Disponível em: https://download.inep. gov.br/educacao_superior/ avaliacao_cursos_graduacao/instrumentos/2015/ instrumento_cursos_graduacao_publicacao_agosto 2015.pdf. Acesso em: 14 jan. 2021.

8. Declaração foi dada pelo Diretor-Geral da Organização Mundial de Saúde, Tedros Adhanom Ghebreyesus. Ver: OMS DECRETA pandemia mundial por novo coronavírus. 0 Globo, São Paulo, 11 mar. 2020. Disponível em: https://oglobo.globo.com/ sociedade/coronavirus/ oms-decreta-pandemia-mundial-por-novo-coronavirus-24298652. Acesso em: 14 jan. 2021.

9. FREIRE, Paulo. Carta de Paulo Freire aos professores. Estudos Avançados, São Paulo v.15, n.42, p.259-268, 2001. Disponível em: http://www.scielo.br/ scielo.php?script $=$ sci arttext\&pid = S0103 40142001000200013\&lng $=e n \& n r m=i s o$. Acesso em: 14 jan. 2021.
Questões técnicas de conexão continuavam sendo utilizadas para justificar a ausência no decurso completo da aula e mesmo os estudantes que se mostravam on-line não pareciam estar presentes ou ao menos responsivos. Ao mesmo tempo, o horizonte descortinava uma realidade concreta demais para ser ignorada: o avanço da doença no país e o crescente e assustador número de infectados e mortos. O mundo em pandemia, que parecia tão distante naquela sexta-feira 13, passou a ocupar o centro dos debates e discussões nas aulas remotas.

Se o mundo adoecido está no centro das atenções (e tensões) de professora e estudantes no contexto do Ensino Remoto Emergencial, é preciso aprender a ler esse mesmo mundo e, nesse processo, transformá-lo e transformar-se. Ao assumir a perspectiva freireana ${ }^{6}$ de que toda prática educativa precisa da situação concreta, da realidade, como condição de existência para formular uma postura permanentemente crítica, quero destacar a hipertransversalidade da Covid-19 ao longo de todo o desenvolvimento da disciplina; mais do que uma simples tematização dos conteúdos, a pandemia se mostrou tanto um acontecimento que merecia escrutínio quanto um estruturador das relações nessa "nova" sala de aula, experimentada de maneira tão intempestiva.

A hipertransversalidade da Covid-19 que postulo neste relato deve ser entendida a partir de duas perspectivas: na primeira, é preciso tomá-la a partir da referência aos temas transversais e sua importância no currículo da educação superior. Trata-se de um assunto ou conteúdo de natureza social que não se configura como disciplina e que possui características interdisciplinares, precisando ser tratado de forma transversal na matriz curricular ${ }^{7}$. Minha experiência no semestre de Educação Remota Emergencial enfatiza o impacto na reconfiguração dos conteúdos em função da experiência inédita de atravessar a maior crise sanitária do planeta no último século ${ }^{8}$. Assumo a premissa de que a prática ensinante como leitura do mundo prevê uma experiência de compreensão que associa (em vez de colocar em dicotomia) conceitos ${ }^{9}$. Essa capacidade associativa tematizou a pandemia nas aulas de teorias do jornalismo e produziu reflexões situadas em observações do presente e comparações com experiências do passado no que se refere especificamente à relação entre saúde pública e meios de comunicação.

Pude observar que uma parte significativa das aulas terminava levando inevitavelmente a uma leitura sobre o jornalismo interessado nas questões do momento, nas repercussões da pandemia no Brasil e no mundo. Debatemos, por exemplo, o agendamento constante da Covid-19 no espaço público; a mudança nas estratégias de negócio de alguns meios de comunicação; a organização da produção editorial em função da pandemia e a mudança nas rotinas produtivas observadas nos telejornais locais e nacionais. Temas que, visto numa perspectiva geral, já estavam previstos no planejamento inicial, mas que assumiram uma outra "consistência" quando atravessados pela temática da Covid-19.

A segunda perspectiva da hipertransversalidade deve considerar a circunstância irresistível que estávamos atravessando; afinal, se não fosse a pandemia e seus efeitos de isolamento, as aulas remotas sequer seriam concebidas para 
a realização do semestre. Nesse sentido, tudo diz respeito à Covid-19 quando se trata da experiência de Educação Remota Emergencial da primeira metade de 2020 e suas burocracias: da (re)organização do calendário acadêmico às novas políticas de autorização de aula remota, passando pela regulamentação de estágios realizados em home office e a viabilidade de realização de cerimônias (virtuais) de colação de grau. Esse duplo (curricular e burocrático) dão o sentido de hipertransversalidade que postulo no relato, uma vez que os sentidos da pandemia não só atravessam o currículo e seus conteúdos como ocupam também as discussões sobre a própria viabilidade da educação em situações de isolamento e incerteza.

\section{DESAFIANDO A HIPERTRANSVERSALIDADE DA COVID-19}

Um assunto, no entanto, foi capaz de redefinir o cenário saturado por boletins médicos e curvas de infecção; aconteceu na aula do dia 22 de maio, quando a turma discutir demonstrou interesse na discussão das repercussões da entrevista que o Youtuber/influenciador Felipe Neto concedeu ao programa televisivo Roda Viva, da TV Cultura. Encontrei uma turma extremamente mobilizada pelo programa (transmitido ao vivo na segunda-feira, 18 de maio de 2020) e por algumas colocações do entrevistado.

Àquela altura do planejamento acadêmico, estávamos começando a trabalhar com alguns temas da cibercultura associados ao jornalismo e aquela entrevista, que a princípio poderia ser tratada como um buzz típico da internet, assumiu um papel central no fechamento da disciplina nas aulas seguintes. Os estudantes insistiam em discutir as "motivações" por trás do posicionamento político do youtuber ao se opor ao governo Bolsonaro. Apontei o risco de conduzir a discussão numa perspectiva tão maniqueísta e decidimos assistir juntos alguns trechos do programa. Destaquei um ponto sensível da entrevista, em que Felipe Neto falava sobre estratégias de comunicação e como o bolsonarismo vem se mostrando bastante eficiente em se comunicar com as pessoas. Na entrevista, inclusive, ele afirma em vários momentos o papel e a importância do jornalismo no contexto de desinformação que o Brasil está atravessando - mas foi na resposta à jornalista Rachel Sherazade que nos detivemos com mais atenção: a pergunta versava sobre como informações de qualidade (mediadas pelo paywall $^{10}$ ) poderiam competir com as fake news, distribuídas gratuitamente. A reposta foi a seguinte:

Os grandes veículos, na minha concepção [...] deveriam repensar como eles estão fazendo paywall, que é aquilo que todo mundo "ama": vai abrir uma notícia e é só para assinante. Nesse momento tem muita gente ficando muito irritada com isso. Por que as pessoas vão ficando irritadas com isso? Porque não está sendo feito da maneira mais inteligente. É preciso rever a maneira como se está sendo feito. [...] Você só vai ler se você for assinante. Às vezes você tem que fisgar a pessoa,

10. Também conhecido como "acesso pago", é um método de restrição de acesso a determinados conteúdos mediante pagamento de assinatura. 
11. FELIPE Neto comenta estratégias de comunicação dos veículos jornalísticos. [S. I.: s. n.], 2020. 1 vídeo (2 min.). Publicado pelo canal Roda Viva. Disponíve em: https://www.youtube. $\mathrm{com} / \mathrm{watch}$ ?reload $=9 \& \mathrm{v}=-$ $1 \mathrm{fGb} 79 \mathrm{bToms}$. Acesso em: 14 jan. 2021

12. IRETON, Cherilyn; POSETTI, Julie (org.). Jornalismo, fake news e desinformação: manual para educação e treinamento em jornalismo. Paris: Unesco, 2019.

13. Idem.

14. Para tratar com a turma como a ideia de crise persiste no processo de compreensão do jornalismo sugeri a leitura de BARROS E SILVA, Fernando de. O jornalismo como crise permanente. Folha de S.Paulo São Paulo, 1 fev. 2002. Disponivel em: https://www1. folha.uol.com.br/folha/80anos/futuro.shtml Acesso em: 14 jan. 2020.

15. PIRES, Breiller. Movimento expõe empresas do Brasil que financiam, via anúncios, sites de extrema direita e notícias falsas. El País, São Paulo, 20 maio 2020. Disponível em: https://brasil.elpais. com/brasil/2020-05-20/ movimento-expoe-empresas-do-brasil-que-financiam-via-publicidadesites-de-extrema-direita-e-que-propagam-noticias-falsas.html. Acesos em: 14 jan; 2021 encantá-la e fazê-la ser uma assinante, reservando determinadas coisas para assinantes. Quando você coloca tudo para assinantes, como eu tenho visto acontecer em alguns veículos, você acaba causando uma rejeição [...] O grande problema do paywall hoje é que você elitiza a informação de qualidade, a pessoa que não tem condição de assinar não consegue saber a verdade sobre determinado assunto e só recebe a informação pelo Whatsapp. Então os grandes veículos, a Folha, o Estadão, Valor, Globo, todos os grandes veículos, precisam rever as estratégias de paywall. Primeiro de tudo pensar é preciso que a informação básica sobre a realidade do que a gente está vivendo alcance as camadas mais pobres e você não pode elitizar esse tipo de informação, num momento tão delicado de Fake News como a gente está vivendo. Então essas matérias precisam ser gratuitas e entender de que forma usar o algoritmo e os robôs para trazer assinantes e não perdê-los, como está acontecendo agora ${ }^{11}$.

Não é objetivo desse relato comentar a validade ou consistência da resposta de Felipe Neto para o debate sobre fake news e desinformação, ou sobre as estratégias de financiamento on-line. No entanto, é oportuno trazer à cena algumas premissas com as quais o trabalho se alinha e que foram aprofundadas durante as aulas: entre elas, está a proposta defendida por Ireton e Posseti, para a Unesco, de que a expressão fake news é na verdade um "oxímoro que se presta a danificar a credibilidade da informação que de fato atende ao limiar de verificabilidade e interesse público - isto é, notícias reais" ${ }^{12}$. Por outro lado, a desinformação seria a composição de uma série de "tentativas deliberadas (frequentemente orquestradas) para confundir ou manipular pessoas por meio de transmissão de informações desonestas"13. A desinformação, nesse sentido, é elaborada como um projeto de objetivos políticos claros e de amplos recursos de produção e distribuição automatizada.

Insisti com a turma que qualquer debate sobre a circulação das notícias (sejam elas verificadas ou as fake news) e o escopo da desinformação deveria levar em consideração a viabilidade do negócio jornalístico e entendê-lo em seu funcionamento, não para necessariamente (ou apenas) encantar potenciais leitores e transformá-los em assinantes - como o youtuber sugeriu em sua reposta. Debater o modelo de negócio é uma parte fundamental do quebra-cabeça da crise permanente do jornalismo ${ }^{14}$, mas também se mostrou uma forma muito eficiente de acessar o tema das fake news em sua ambiguidade. Assim, me desfiz do planejamento inicial (baseado mais numa discussão sobre a verdade como efeito e a dessubstancialização do discurso da verdade nas sociedades contemporâneas) e trouxemos para o centro da aula um texto do jornal El País publicado no dia 20 de maios de 2020: "Movimento expõe empresas do Brasil que financiam, via anúncios, sites de extrema direita e notícias falsas"15. A leitura do texto, juntamente com o conhecimento prévio de que a maioria dos estudantes já tinha sobre o movimento de que falava a matéria, o Sleeping Giants, provocou outra alteração no planejamento da disciplina. Decidimos, juntos, que o trabalho de composição da nota da segunda unidade seria uma apresentação de grandes casos jornalísticos associados a conceitos importantes identificados na matéria e que formam o que chamamos de "economia das fake 
news". Com a turma dividida em três grupos, cada um deles deveria construir a apresentação a partir de um dos seguintes conceitos: monetização ${ }^{16}$, mídia programática $^{17}$ e funcionamento do Google Ad Sense ${ }^{18}$. O resultado foi um evento on-line de culminância que antecedeu a avaliação da segunda unidade.

Essa prática, que compreendeu cerca de três aulas/videoconferências além da apresentação dos grupos, foi como os próprios estudantes pontuaram: uma espécie de "respiro" em relação à tematização constante da Covid-19 em seus cotidianos (acadêmico e doméstico). Estávamos, como foi dito na aula de fechamento e avaliação da disciplina, adoecidos pela hipertransversalidade do coronavírus, uma vez que além de interferir na condução do semestre on-line e nas nossas vidas privadas (e quarentenadas), uma parte significativa do planejamento da disciplina foi pautado pelo vírus. Entendo e defendo que a transversalidade é fundamental para o pensamento complexo ${ }^{19}$, mas a experiência da hipertransversalidade foi particularmente desafiadora - isso porque a pandemia se impôs inevitavelmente como tematização central das interações, o que impediu a diversidade de debates sobre temáticas que, na formação jornalística, são indispensáveis.

\section{CONSIDERAÇÕES FINAIS}

É curiosa essa situação de olhar para uma experiência tão recente e vivida com tantos desafios e extrair dela uma narrativa consistente, com início e fim. Faz pensar sobre a ilusão biográfica de que Bourdieu ${ }^{20}$ falava para explicar como o relato biográfico aceita e legitima o "postulado da existência narrada" Nessa perspectiva, os acontecimentos se organizam seguindo relações inteligíveis, mais do que por uma determinação cronológica. A experiência docente em plena pandemia mostrou como as "relações inteligíveis" entre os acontecimentos só fazem sentido porque o semestre se encerrou, dando espaço para uma avaliação minimamente distanciada. Ao longo desse primeiro semestre, muitas vezes dividi com colegas se estávamos mesmo fazendo a coisa certa; se nossas escolhas eram as mais apropriadas e quais lacunas estávamos deixando passar na formação dos estudantes. E, muito embora seja importante reconhecer a tenacidade e competência dos profissionais docentes em assumirem a tarefa do Ensino Remoto Emergencial sem qualquer planejamento prévio ou treinamento e movidos apenas pelos imperativos de uma pandemia, é igualmente importante pensar os custos envolvidos nessa tarefa.

Falo não apenas dos custos pedagógicos, mas daqueles "invisíveis", que se manifestam numa situação de exaustão de professora e estudantes. Isso significa ponderar, por exemplo, a respeito da composição entre atividades síncronas e assíncronas que o modelo de educação remota enseja. Assumir que há aula, um evento central no planejamento acadêmico, apenas quando há a reprodução do encontro com a turma numa relação síncrona mostrou-se, no decurso de um semestre, extremamente cansativo. Assim, entendo que é necessário pensar as
16. Monetização é a relação comercial entre uma determinada plataforma e seus produtores de conteúdo. Quanto mais relevante um determinado conteúdo (visualizações, interações etc.), mais anunciantes ele atrai, gerando mais valor.

17. Processo de compra e venda de espaços publicitários online que permite que $o$ anunciante personalize sua mensagem para um determinado nicho, em momento e contexto exatos. É diferente da mídia broadcasting, que se caracteriza pela disseminação da mensagem de maneira massiva.

18. Programa em que anunciantes pagam ao Google pela exibição de anúncios em blogs e sites afiliados em áreas previamente determinadas pelo administrador.

19. MORIN, Edgar. Introdução ao pensamento complexo. 5. ed. Lisboa: Instituto Piaget, 2008.

20. BOURDIEU, Pierre. A ilusão biográfica. In: FERREIRA, M. M.; AMADO, Janaína. Usos e abusos de história oral. Rio de Janeiro: Editora FGV, 1996. p. 183-191.

21. Idem, p. 184. 
atividades assíncronas para além de uma função de complementação de carga horária. Nessa perspectiva, entendo que é fundamental um debate sobre o contrato pedagógico nas circunstâncias do ensino remoto (sendo ele emergencial ou não). A ênfase nos encontros síncronos como os únicos realizadores da aula reforça o discurso de que professoras e professores precisam "se reinventar" no formato remoto, quando, na verdade, o que acontece é um acúmulo de funções e de desenvolvimento de novas habilidades, gerando sobrecarga e precarização. O meme abaixo, compartilhado em todos os grupos de comunicação entre professores dos quais faço parte, ilustra bem como esse processo se deu. A potência cômica da peça aponta para futuras reflexões sobre as condições de trabalho de professoras e professores num contexto de ensino remoto, mesmo depois de superadas as condições emergenciais da pandemia e do isolamento.

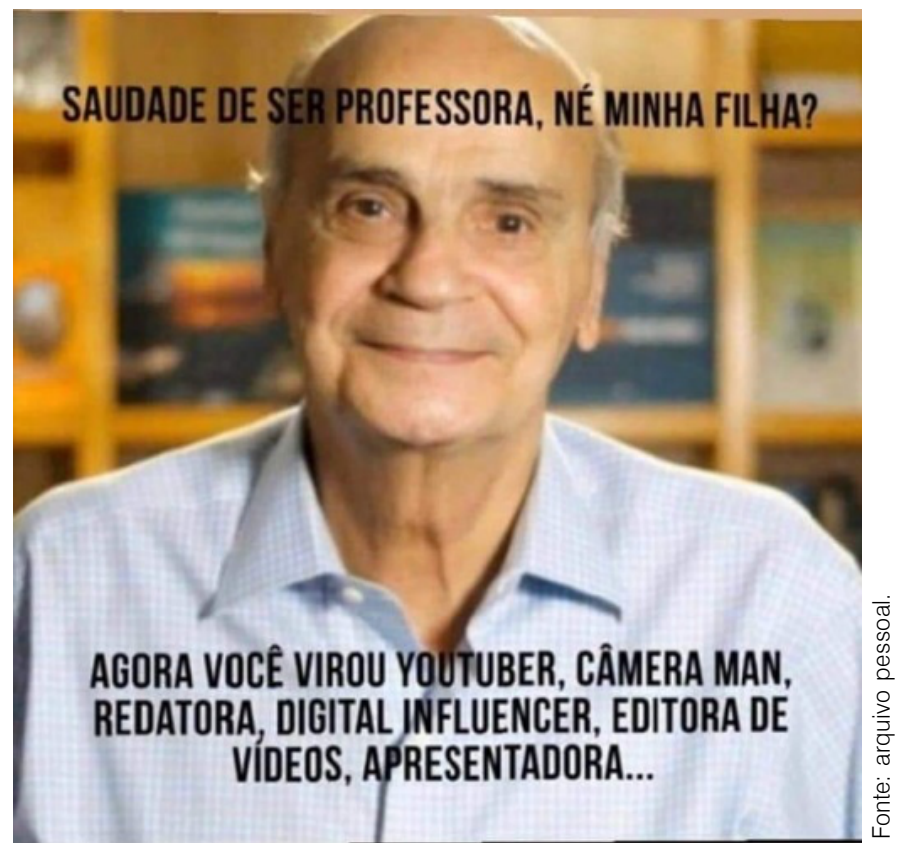

Figura 1: Meme compartilhado entre professoras e professores

Acredito que é necessário mais algum tempo para elaborar melhor e com mais consistência os impactos do ensino remoto emergencial na educação brasileira como um todo e no ensino superior especificamente. No entanto, algumas projeções sinalizam um quadro em que as plataformas online de ensino assumem protagonismo. Segundo pesquisa da Associação Brasileira das Mantenedoras de Ensino Superior (ABMES) ${ }^{22}$, a quase totalidade dos estudantes matriculados na rede privada pretende continuar a estudar, mas cerca da metade (42\%) acredita que há um risco de desistência devido a complicações econômicas causadas pelo Coronavírus. A mesma pesquisa informa que já em 2022, haverá mais estudantes matriculados em cursos superiores EaD do que em cursos presenciais. 
Num cenário próximo de inevitável plataformização do ensino superior privado, o contexto emergencial certamente não será o tom da experiência da educação remota e é bem possível que fórmulas híbridas (de encontros presenciais e virtuais) sejam experimentadas. Nesse sentido, as questões sobre os contratos didáticos estarão melhor estabelecidas e devidamente burocratizadas pelas instituições de ensino. A hipertransversalidade da pandemia, por outro lado, parece que vai persistir por mais tempo. Observa-se nas chamadas de dossiês, na formação de grupos de estudo, na criação de coleções, na publicação de números temáticos de revistas, etc. No momento em que finalizo a redação desse relato, acompanho a publicação no jornal americano New York Times de um vídeoeditorial do próprio Felipe Neto $^{23}$ falando sobre como Jair Bolsonaro é o pior presidente do mundo a conduzir um país na crise do Coronavírus, pior que Trump, inclusive. É inevitável pensar como esse conteúdo provocaria discussões interessantes com a turma, que agora aproveita as merecidas férias de julho. Pelo menos por ora, ler e compreender o mundo como prática docente é uma atividade que não poderá ser separada da proposta de ler e compreender as contingências e consequências da pandemia, mesmo com Felipe Neto ao lado.

\section{REFERÊNCIAS}

ALFANO, Bruno. "Há uma crise de atenção". O Globo, 12 set. 2015. Disponível em: https://oglobo.globo.com/sociedade/educacao/ha-umacrise-de-atencao-17476629. Acesso em: 14 jan. 2021.

BARROS E SILVA, Fernando de. O jornalismo como crise permanente. Folha de S.Paulo, São Paulo, 1 fev. 2002. Disponível em: https://www1.folha.uol. com.br/folha/80anos/futuro.shtml Acesso em: 14 jan. 2020.

BRASIL, Ministério da Educação. Instituto Nacional de Estudos e Pesquisas Educacionais Anísio Teixeira. Diretoria de Avaliação da Educação Superior. Sistema Nacional de Avaliação da Educação Superior. Instrumento de avaliação de cursos de graduação: presencial e a distância. Brasília, 20 mar. 2015. Disponível em: https://download.inep.gov.br/educacao_superior/ avaliacao_cursos_graduacao/instrumentos/2015/instrumento_cursos_ graduacao_publicacao_agosto_2015.pdf. Acesso em: 14 jan. 2021.

BRASIL TERÁ maioria de alunos em EAD até 2022, indica estudo. GaúchaZH, Porto Alegre,10 jun. 2020. Disponível em: https://gauchazh.clicrbs.com. br/educacao-e-emprego/amp/2020/06/brasil-tera-maioria-de-alunos-emmodalidade-ead-em-2022-ckb9g9b840074015n6ap9avya.html. Acesso em: 14 jan. 2021.

BOURDIEU, Pierre. A ilusão biográfica. In: FERREIRA, M. M.; AMADO, Janaína. Usos e abusos de história oral. Rio de Janeiro: Editora FGV, 1996. p. 183-191.

23. NETO, Felipe. Trump isn't the worst pandemic president. The New York Times, New York, 15 jul. 2020. Disponível em: https://www.nytimes. com/2020/07/15/opinion/ coronavirus-covid-brazil-bolsonaro.html. Acesso em: 14 jan. 2021. 
CANZIAN, Fernando. A revolta da classe média. Folha de S.Paulo, São Paulo, 22 jul. 2020. Disponível em: https:/ / temas.folha.uol.com.br/desigualdade-global/ europa/a-revolta-da-classe-media.shtml. Acesso em: Acesso em: 14 jan. 2021.

FELIPE Neto comenta estratégias de comunicação dos veículos jornalísticos. [S. l.: s. n.] , 2020. 1 vídeo (2 min.). Publicado pelo canal Roda Viva. Disponível em: https://www.youtube.com/watch? reload=9\&v=1fGb79bToms. Acesso em: 14 jan. 2021.

FREIRE, Paulo. A importância do ato de ler: em três textos que se completam. 3. ed. São Paulo: Autores Associados: Cortez, 1986.

FREIRE, Paulo. Carta de Paulo Freire aos professores. Estudos Avançados, São Paulo, v. 15, n. 42, p. 259-268, 2001. Disponível em: http://www.scielo. br/scielo.php?script=sci_arttext\&pid=S0103-40142001000200013\&lng=en\&n rm=iso. Acesso em 14 jan. 2021.

FREIRE, Paulo. Professora sim, tia não: cartas a quem ousa ensinar. 14. ed. São Paulo: Olho d'Água, 2003.

GOING online without any proper help. Canadian Association of University Teachers, Ottawa, 1 maio 2020. Disponível em: https://www.caut.ca/ bulletin/2020/05/news-going-online-without-any-proper-help. Acesso em: 14 jan. 2021.

IRETON, Cherilyn; POSETTI, Julie (org.). Jornalismo, fake news e desinformação: manual para educação e treinamento em jornalismo. Paris: Unesco, 2019.

LI, Charlene; BERNOFF, Josh. Groundswell. Boston: Harvard Business Press, 2008.

MENEZES, Anna Paula de Avelar Brito. Contrato didático e transposição didática: inter-relações entre fenômenos didáticos na iniciação à álgebra na $6^{\text {a }}$ série do ensino fundamental. 2006. Dissertação (Mestrado em Educação) - Centro de Educação, Universidade Federal de Pernambuco, Recife, 2006.

MORIN, Edgar. Introdução ao pensamento complexo. 5. ed. Lisboa: Instituto Piaget, 2008.

NETO, Felipe. Trump isn't the worst pandemic president. The New York Times, New York, 15 jul. 2020. Disponível em: https://www.nytimes. com/2020/07/15/opinion/coronavirus-covid-brazil-bolsonaro.html. Acesso em: 14 jan. 2021.

OMS DECRETA pandemia mundial por novo coronavírus. O Globo, São Paulo, 11 mar. 2020. Disponível em: https://oglobo.globo.com/ sociedade / coronavirus / oms-decreta-pandemia-mundial-por-novocoronavirus-24298652. Acesso em: 14 jan. 2021. 
PIRES, Breiller. Movimento expõe empresas do Brasil que financiam, via anúncios, sites de extrema direita e notícias falsas. El País, São Paulo, 20 maio 2020. Disponível em: https://brasil.elpais.com/brasil/2020-05-20/ movimento-expoe-empresas-do-brasil-que-financiam-via-publicidade-sites-deextrema-direita-e-que-propagam-noticias-falsas.html. Acesos em: 14 jan; 2021.

WINQUES, Kérley. “Tem que ler até o fim?": consumo da grande reportagem multimídia pelas gerações X, Y e Z nas multitelas. 2016. Dissertação (Mestrado em Jornalismo) - Departamento de Jornalismo, Universidade Federal de Santa Catarina, Florianópolis, 2016. 